\title{
PENGARUH APLIKASI KOMPOS HIJAUAN Mucuna bracteata DAN MIKORIZA TERHADAP KADAR HARA P DAN PERTUMBUHAN BIBIT KELAPA SAWIT (Elaeis guineensis Jacq)
}

\author{
Mardiana Wahyuni*, Rina Maharany, Aulia Cahya Hasyanah Dlm. \\ Program Studi Budidaya Perkebunan STIPAP Medan 20226 \\ *Corresponding author: mardiana@stipap.ac.id
}

\begin{abstract}
ABSTRAK
Hal penting dalam pemeliharaan bibit kelapa sawit adalah pemupukan. Tanah sebagai media tumbuh pada penanaman di dalam polybag memiliki keterbatasan sumber hara dalam memberi nutrisi tanaman. Penggunaan pupuk organik dapat memperbaiki sifat fisik, kimia dan biologi tanah, dan membantu melepaskan unsur hara dari ikatan koloid tanah. Mikoriza berfungsi memperpanjang dan memperluas jangkauan akar sehingga meningkatkan penyerapan unsur hara. Penelitian ini dilaksanakan bulan Desember-Juni 2019 di STIPAP Medan. Menggunakan Rancangan Ancak Kelompok (RAK) Kompos dengan taraf K0, K1, K2 dan dosis $0 \mathrm{~kg}, 0.6 \mathrm{~kg}, 1.2 \mathrm{~kg}$. Serta Mikoriza M1, M2, M3 dengan dosis $0 \mathrm{~g}, 20 \mathrm{~g}, 40 \mathrm{~g}$. Parameter yang diamati yaitu tinggi bibit, jumlah daun, berat kering tajuk, berat kering akar dan kadar hara $\mathrm{P}$ daun. Perlakuan terbaik adalah K2M2 (1.2kg kompos dan $40 \mathrm{~g}$ Mikoriza).
\end{abstract}

Kata kunci : Kompos hijauan, Mucuna Bracteata, Mikoriza

The important thing about oil palm seedlings is maintenance and fertilization. Soil as a medium of the plant in polybags has limited nutrient sources in providing plant nutrition. The use of organic fertilizers can improve the physical, chemical, and biological properties of the soil, and help release nutrients from soil colloid bonds. Mycorrhizae have the function of extending and expanding the reach of the roots thereby increasing the absorption of nutrients. This research was conducted in December-June 2019 at STIPAP Medan. Using randomized blok design (RBD), a compost group with levels of K0, K1, $\mathrm{K} 2$, and doses of $0 \mathrm{~kg}, 0.6 \mathrm{~kg}, 1.2 \mathrm{~kg}$. As well as mycorrhizae M1, M2, M3 at a dose of $0 \mathrm{~g}$, $20 \mathrm{~g}, 40 \mathrm{~g}$. Parameters observed were seed height, a number of leaves, shoot dry weight, root dry weight, and leaf $\mathrm{P}$ nutrient content. The best treatment was K2M2 $(1.2 \mathrm{~kg}$ compost and 40g Mycorrhizae).

Keywords; Green manure, Mucuna Bracteata, Mycorrhiza

\section{PENDAHULUAN}

Penggunaan bibit yang berkualitas merupakan faktor utama yang memberi pengaruh terhadap produktivitas tanaman kelapa sawit. Upaya peningkatan efektivitas dan efisiensi pemupukan perlu dilakukan agar produksi tanaman kelapa sawit dapat terus meningkat (Paramananthan, 2013).

Penggunaan pupuk organik dapat memperbaiki sifat fisik, kimia dan biologi tanah, serta membantu melepaskan unsur hara dari ikatan koloid tanah. Selain itu, unsur hara yang mudah hilang akibat penguapan atau terbawa oleh perkolasi air. Dengan adanya pemberian pupuk organik tersebut unsur hara akan diikat sehingga tidak mudah tercuci dan dapat tersedia bagi tanaman (Paramananthan, 2013). Pupuk 
hijau jenis leguminosa yang dapat digunakan adalah Mucuna bracteata yang mempunyai kandungan hara (utamanya nitrogen) yang relatif tinggi dibanding jenis tanaman lainnya. Mucuna bracteata sebagai bahan organik mengandung nitrogen $(\mathrm{N}) 3,71 \%$, fosfor (P) 0, $38 \%$, kalium (K) 2,92\%, kalsium (Ca) 2,02\%, magnesium (Mg) 0,36\%, Corganik 31,4\% dan $\mathrm{C} / \mathrm{N} 8,46 \%$ (Simamora \& Salundik, 2006).

Selain itu jenis fungi dapat membantu dalam meningkatkan efisiensi pemupukan. Penggunaan fungi mikoriza merupakan salah satu upaya yang dapat dilakukan untuk mempercepat pertumbuhan tanaman Supriyanto (1999).

Fungi Mikoriza bermanfaat dalam memperluas perkembangan zona perakaran sehingga dapat meningkatkan serapan unsur hara (Kartika, 2007).

Hifa Mikoriza yang berkembang di luar akar dapat menyerap unsur hara dan air dari tanah untuk diberikan kepada tanaman inangnya. Hifa Mikoriza juga memiliki afinitas yang lebih tinggi terhadap fosfor dibandingkan rambut akar. Enzim fosfatase yang dihasilkan oleh hifa Mikoriza juga merupakan salah satu mekanisme yang dilakukan oleh fungi Mikoriza ini dalam meningkatkan serapan unsur $\mathrm{P}$ oleh tanaman (Smith et al., 2011).

Unsur hara Phosfor (P) memiliki peran penting bagi tanaman diantaranya pembentukan sel dan lemak albium, pembentukan bunga, buah dan biji, kematangan tanaman, dapat melawan efek nitrogen, merangsang perkembangan akar, dan dapat meningkatkan kualitas tanaman (Damanik et al., 2010).

\section{BAHAN DAN METODE}

Penelitian dilakukan di areal pembibitan Sekolah Tinggi Ilmu Pertanian Agrobisnis Perkebunan (STIPAP). Pada bulan Desember 2018- Juni 2019.

Bahan yang digunakan Bibit tanaman kelapa sawit berumur 3 bulan dari PPKS varietas DxP Dumpy, kompos hijauan Mucuna bracteata yang dibuat terlebih dahulu, Tanah Ultisol, Mikoriza yang diperoleh dari laboratorium Fakultas
Pertanian USU. Alat yang digunakan polybag, tong dan ember, timbangan, meteran kain, cangkul, alat alat pendukung lainnya.

Penelitian ini menggunakan metode Rancangan Ancak Kelompok (RAK) dengan 2 faktor. Faktor pertama adalah kompos hijauan Mucuna bracteata terdiri dari 3 taraf dosis Kompos hijauan Mucuna bracteata yaitu K0: (tanpa Kompos), K1: 0,6kg kompos/bibit, dan K2: 1,2 kg kompos/bibit. Dan faktor ke dua adalah Mikoriza ,terdiri dari 3 taraf dosis Mikoriza yaitu M0: (tanpa Mikoriza), M1: 20 gram Mikoriza/bibit, dan M2: 40 gram Mikoriza/bibit.

Pelaksanaan penelitian ini meliputi; i.pembuatan kompos hijauan M. bracteata, ii.persiapan media tanam, penanaman dan iii.pemeliharaan, aplikasi perlakuan, pengamatan pada tanaman, pembongkaran tanaman dan analisis data. Parameter yang diamati yaitu tinggi bibit, jumlah daun, berat kering tajuk, berat kering akar dan kadar hara $\mathrm{P}$ daun.

\section{HASIL DAN PEMBAHASAN}

\section{Tinggi Bibit}

Hasil pengamatan pertumbuhan tinggi bibit disajikan pada Tabel 1. keragaman pengukuran $\mathrm{pH}$ tanah dapat dilihat pada Tabel 1 berikut : 
Tabel 1 Rataan Tinggi Bibit Kelapa Sawit Dengan Perlakuan Kompos Dan Mikoriza.

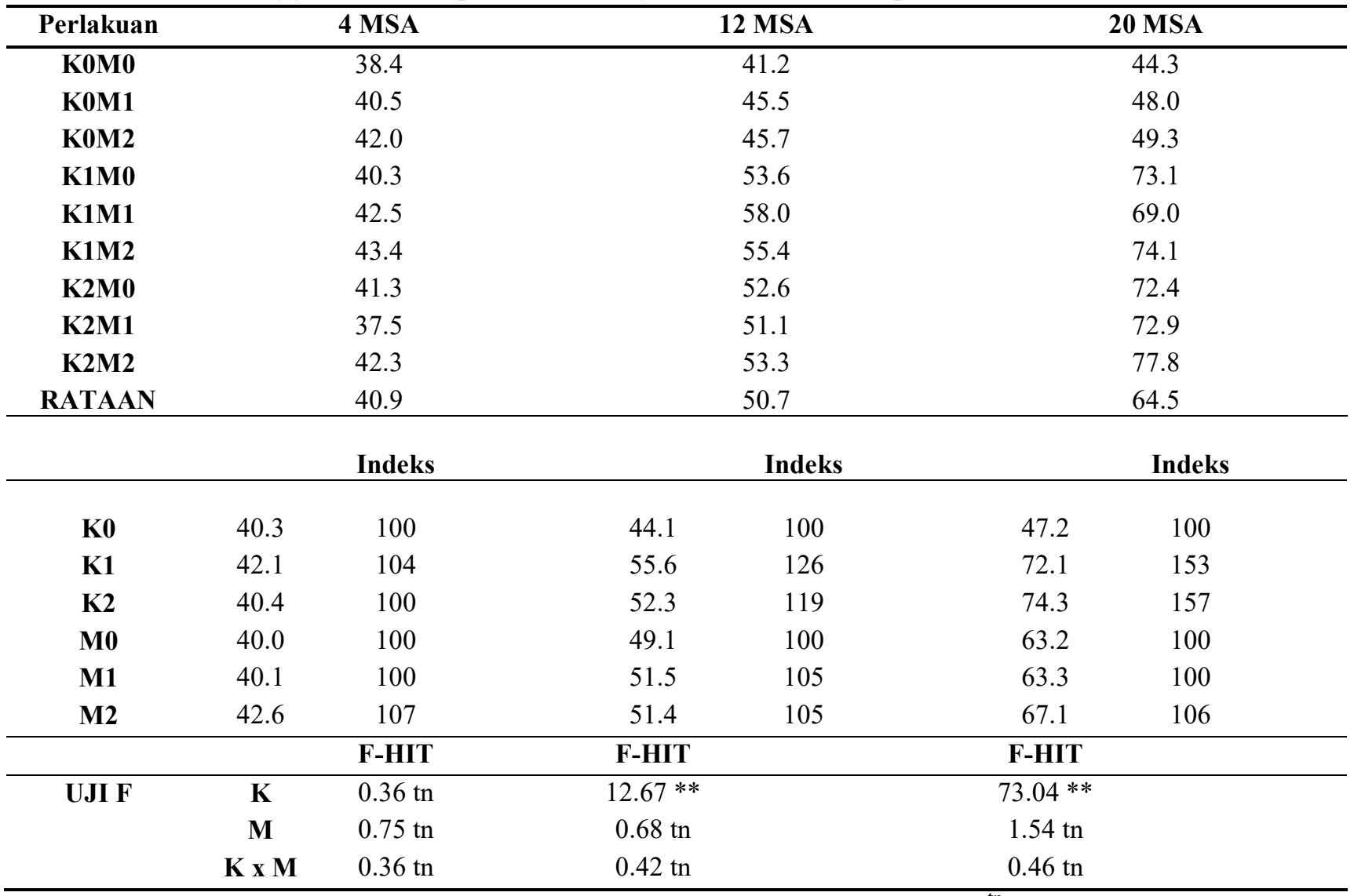

Keterangan : MSA (Minggu Setelah Aplikasi) ; Satuan $\mathrm{cm} ; * *$ Sangat Nyata $;{ }^{\text {tn }}$ tidak nyata

Perlakuan kompos hijauan $\mathrm{M}$. bracteata berpengaruh sangat nyata terhadap pertumbuhan tinggi bibit pada 12 MSA dan 20 MSA. Disebabkan tingginya kandungan hara pada kompos tersebut. Unsur N, P, dan $\mathrm{K}$ berperan dalam pertumbuhan tinggi tanaman karena membantu metabolisme karbohidrat dan mempercepat pertumbuhan jaringan meristematik (Nyakpa et al., 1988).

Aplikasi Mikoriza tidak berpengaruh nyata terhadap pertumbuhan bibit. Mikoriza merupakan fungi atau jamur yang memiliki sifat simbiotik mutualisme. Adapun faktor yang mempengaruhi efektifitasnya adalah kelembapan dan suhu maupun sinar matahari yang sangat menentukan jumlah Mikoriza yang terbentuk (Fakuara, 1988). Interaksi perlakuan kompos hijauan Mucuna bracteata dan aplikasi Mikoriza tidak berpengaruh nyata terhadap pertumbuhan tinggi bibit.

\section{Jumlah Daun}

Hasil pengamatan pertumbuhan jumlah daun bibit disajikan pada Tabel 2.

Tabel 2 Rataan Jumlah Daun Bibit Kelapa Sawit Dengan Perlakuan Kompos Dan Mikoriza.

\begin{tabular}{cccc}
\hline Perlakuan & 4 MSA & 12 MSA & 20 MSA \\
\hline K0M0 & 6.3 & 9.0 & 9.8 \\
K0M1 & 6.3 & 8.3 & 9.5 \\
K0M2 & 6.3 & 7.8 & 9.0 \\
K1M0 & 5.5 & 9.0 & 11.3 \\
K1M1 & 6.5 & 10.8 & 11.8 \\
K1M2 & 6.3 & 9.3 & 11.3 \\
K2M0 & 6.5 & 9.3 & 11.5 \\
K2M1 & 6.3 & 10.0 & 12.8 \\
K2M2 & 6.3 & 10.3 & 13 \\
RATAAN & 6.3 & 9.3 & 11.1 \\
\hline
\end{tabular}




\begin{tabular}{lcccccc}
\hline & & Indeks & & Indeks & & Indeks \\
\hline K0 & 6.3 & 100 & 8.3 & 100 & 9.4 & 100 \\
K1 & 6.1 & 97 & 9.7 & 117 & 11.4 & 121 \\
K2 & 6.3 & 100 & 9.8 & 118 & 12.4 & 132 \\
M0 & 6.1 & 100 & 9.1 & 100 & 10.8 & 100 \\
M1 & 6.3 & 103 & 9.7 & 107 & 11.3 & 105 \\
M2 & 6.3 & 103 & 9.1 & 100 & 11.1 & 103 \\
\hline & K-HIT & F-HIT & & $20.0 * *$ & \\
\hline UJ F & M & 0.27 tn & $6.5 * *$ & & 0.53 tn & \\
& K $\mathbf{~ M ~}$ & 0.68 tn & 1.09 tn & & 0.98 tn \\
\hline
\end{tabular}

Keterangan : MSA (Minggu Setelah Aplikasi); Satuan helai $; * *$ Sangat Nyata $;{ }^{\text {tn }}$ tidak nyata

Perlakuan kompos hijauan $M$. bracteata berpengaruh sangat nyata terhadap jumlah daun bibit pada 12 MSA dan 20 MSA dikarenakan penyerapan unsur hara dari kompos hijauan Mucuna Bracteata sudah maximal dan mempengaruhi laju fotosintetis pada bibit. Hal ini sesuai dengan (Prawiranata et al., 1981) menyatakan bahwa peningkatan laju fotosintesis akan diiringi dengan peningkatan jumlah daun.

Perlakuan aplikasi Mikoriza tidak berpengaruh nyata terhadap pertambahan jumlah daun tetapi pemberian inokulum
Mikoriza dapat meningkatkan pertumbuhan bibit dan kemampuan bibit untuk memamfaatkan nutrisi yang ada dalam tanah, terutama $\mathrm{P}, \mathrm{N}, \mathrm{Cu}, \mathrm{Mn}, \mathrm{K}$ (Rompas 1997).

Interaksi perlakuan kompos M. bracteata dan aplikasi Mikoriza berpengaruh tidak nyata terhadap pertambahan jumlah helai daun bibit.

\section{Berat Kering Tajuk dan Akar}

Hasil pengamatan berat kering tajuk dan akar bibit disajikan pada tabel 3 .

Tabel 3. Rataan Berat Kering Tajuk Dan Akar Bibit Kelapa Sawit Dengan Perlakuan Kompos dan Mikoriza.

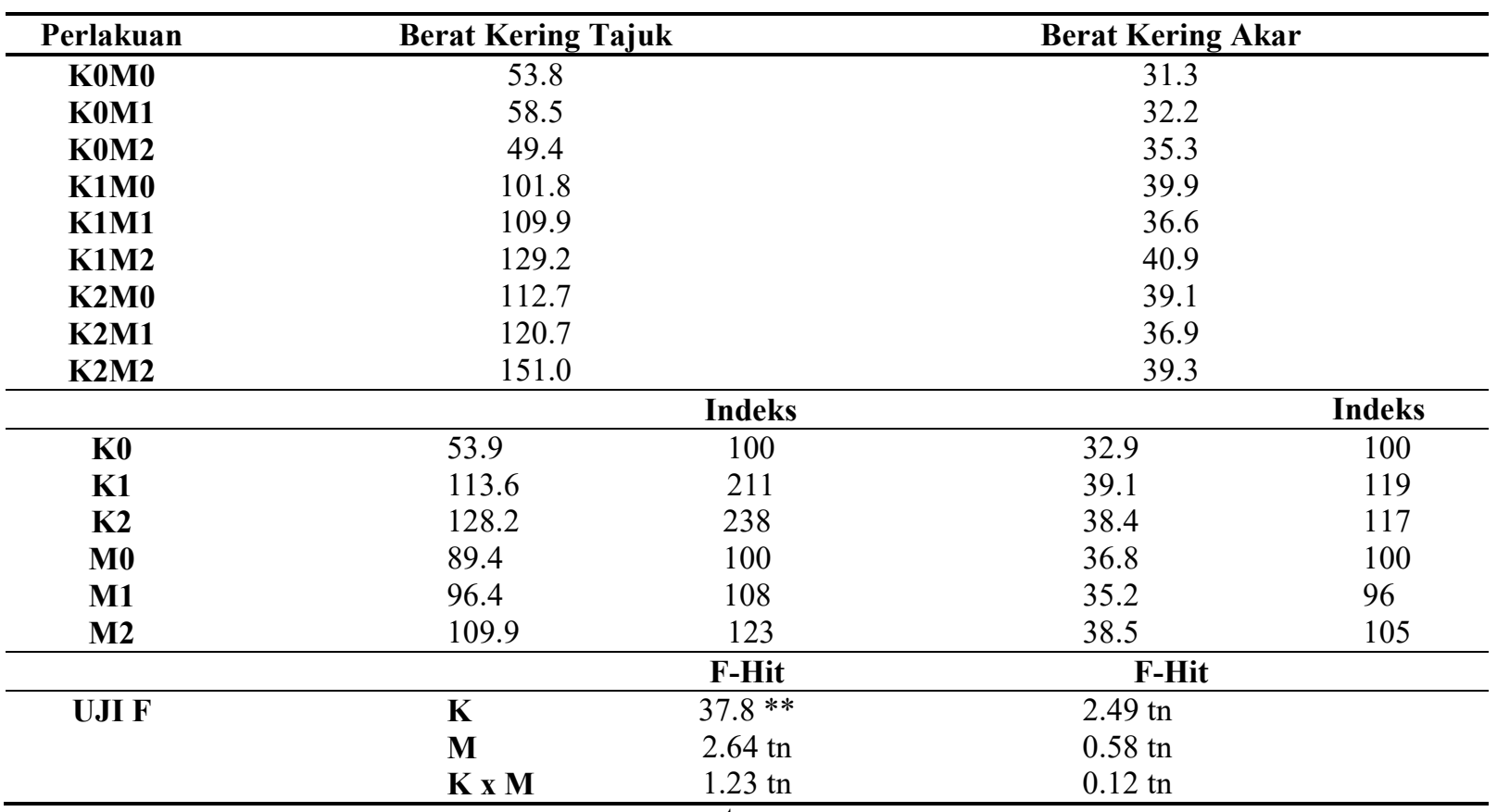

Keterangan : Satuan gram ; ${ }^{* *}$ Sangat Nyata $;{ }^{\text {tn }}$ tidak nyata 
Perlakuan kompos $M$. bracteata berpengaruh sangat nyata terhadap berat kering tajuk, berat kering tajuk mencerminkan serapan unsur hara tanaman dan merupakan indikator yang menentukan kualitas bibit dan ketersediaan unsur hara. Bibit akan tumbuh subur jika unsur hara yang dibutuhkan bibit tersedia dalam jumlah yang cukup dan dapat diserap. Oleh karena itu pertumbuhan vegetatif yang baik akan mempengaruhi berat kering tajuk (Prawiranata et al., 1995).

Perlakuan kompos M. bracteata berpengaruh tidak nyata terhadap berat kering akar, Hasil berat kering akar menunjukkan penyerapan air dan unsur hara oleh akar yang ditranslokasikan ke tajuk tanaman, Pemberian pupuk organik mampu meningkatkan berat kering akar (Sari et al., 2014).

Pada perlakuan Mikoriza berpengaruh tidak nyata terhadap berat kering tajuk dan berat kering akar. Mikoriza berperan dapat mempengaruhi pertumbuhan berbagai jenis tanaman dan juga kandungan fospor tanaman (Anas 1997). Sembiring et all (2018) juga mengemukakan bahwa perlakuan Mikoriza dengan $T$. pinophilus berpengaruh nyata terhadap berat kering bibit kelapa sawit.

Interaksi perlakuan kompos

M.

bracteata dan Mikoriza menunjukan hasil yang tidak berpengaruh nyata pada pengamatan berat kering tajuk dan berat kering akar.

\section{Kadar Fospat Daun}

Hasil pengamatan kadar pospat daun disajikan pada Tabel 4.

Tabel 4. Rataan Kadar Hara Fospat Daun Pada Bibit Kelapa Sawit Dengan Perlakuan Kompos Dan Mikoriza.

\begin{tabular}{|c|c|c|}
\hline \multicolumn{2}{|c|}{ Perlakuan } & P\% \\
\hline \multicolumn{2}{|c|}{ K0M0 } & 1.29 \\
\hline \multicolumn{2}{|c|}{ K0M1 } & 1.65 \\
\hline \multicolumn{2}{|c|}{ K0M2 } & 1.28 \\
\hline \multicolumn{2}{|c|}{ К1M0 } & 1.37 \\
\hline \multicolumn{2}{|c|}{ K1M1 } & 1.65 \\
\hline \multicolumn{2}{|c|}{ K1M2 } & 1.28 \\
\hline \multicolumn{2}{|c|}{ К2М0 } & 1.66 \\
\hline \multicolumn{2}{|c|}{ K2M1 } & 1.37 \\
\hline \multirow{2}{*}{\multicolumn{2}{|c|}{ K2M2 }} & 1.25 \\
\hline & & Indeks \\
\hline Ko & 1.4 & 100 \\
\hline K1 & 1.4 & 100 \\
\hline $\mathbf{K} 2$ & 1.4 & 100 \\
\hline MO & 1.4 & 100 \\
\hline M1 & 1.6 & 114.3 \\
\hline M2 & 1.3 & 92.9 \\
\hline
\end{tabular}

Pemberian kompos hijauan Mucuna bracteata menjunjukkan hasil yang sama pada pelakuan tunggal $\mathrm{K} 0, \mathrm{~K} 1$ dan $\mathrm{K} 2$ dengan dosis $0 \mathrm{~kg}, 0.6 \mathrm{~kg}$ dan $1.2 \mathrm{~kg}$ kompos perpolibag terhadap kadar hara P dengan $1.4 \%$.

Rosmarkam (2002) menyatakan bahwa fosfor berperan dalam proses fotosintesis dan respirasi sehingga sangat penting untuk pertumbuhan secara keseluruhan, selain itu fosfor berperan juga dalam memperbaiki sistem perakaran tanaman.

Perlakuan tunggal pemberian Mikoriza menunjukkan hasil dengan nilai rataan tertinggi pada perlakuan tunggal M1 dosis Mikoriza 20 g terhadap kadar hara P 1.6 $\%$ bibit kelapa sawit.

Interaksi antaran pemberian kompos hijauan Mucuna Bracteata dan Mikoriza menunjukkan hasil nilai rataan tertinggi dengan perlakuan K2M0 dengan dosis kompos $1.2 \mathrm{~kg}$ dan Mikoriza $0 \mathrm{~g}$ terhadap kadar hara $\mathrm{P} 1.66 \%$.

\section{SIMPULAN}

Perlakuan kompos hijauan

M. bracteata berpengaruh sangat nyata terhadap tinggi bibit, jumlah daun, dan berat kering tajuk. Sementara itu perlakuan Mikoriza tidak memberi pengaruh yang nyata terhadap pertumbuhan tinggi bibit, jumlah daun, berat kering tajuk dan akar.

Interaksi antara perlakuan kompos hijauan M. bracteata dan Mikoriza juga tidak pengaruh yang nyata pada semua parameter pengamatan. Perlakuan terbaik adalah K2M2 (1.2kg kompos dan $40 \mathrm{~g}$ Mikoriza).

\section{DAFTAR PUSTAKA}

Anas I. 1997. Respon Pertumbuhan Dan Produksi Kedelai (Glycine Max (L.) Merrill) Yang Diberi Fungi Mikoriza Arbuskular (FMA) Pada Tanah Salin Jurnal AgroekoteknoLogi USU vol 2 (1);421-426.

Damanik, M. M.B., B.E. Hasibuan, Fauzi, Sarifuddin, dan H.Hanum. 2010. Efektifitas Bahan Organik dan Mikoriza Terhadap Pertumbuhan dan 
Serapan Fosfor Bibit Kelapa Sawit. Jurnal Agroestate Vol 7(1);10-11.

Fakuara, M.Y. 1988. Mikoriza Teori dan Kegunaan dalam Praktek. Bogor: Pusat Antar Universitas (PAU) Bioteknologi IPB dan Lembaga Sumber Daya Informasi IPB.

Kartika, E. 2007. Pengujian Efektivitas Fungi Mikoriza Arbuskulab Terhadap Bibit Kelapa Sawit Pada Media Tanah PMK Bekas Hutan dan Bekas Kebun Karet. Jurnal Penelitian Kelapa Sawit. 15(3):151-168.

Nyakpa, M. Y., A. M. Lubis., M. A. Pulung., Amrah, A. G., A. Munawar., G. B Hong, N. Hakim. 1988. Kesuburan Tanah. Universitas Lampung. Bandar Lampung.

Paramananthan, S. 2013. Managing Marginal Soils For Sustainabile Growth Of Oil Palms In The Tropics. J. Oil Palm Environ. 4:1-16.

Prawinata, W. S., Harran dan P. Tdjandronegoro. 1981. Dasar-dasar Fisiologi Tumbuhan II. Fakultas Pertanian IPB. Bogor.

Prawiranata, W, S. Harran dan P. Tjandronegoro. 1995. Dasar - Dasar Fisiologi Tumbuhan II. Fakultas Pertanian IPB. Bogor.

Rompas, J. P. 1997. Pengaruh Pemberian Fungi Mikoriza Arbuskular (Fma) Terhadap Pertumbuhan Dan Produksi Terhadap Pertumbuhan Dan Produksi Beberapa Varietas Tembakau (Nicotiana Tabaccum L.) di lapangan Jurnal Agroekoteknologi USU vol 2(2);586-597.

Rosmarkam, A dan N.W. Yuwono. 2002. Ilmu Kesuburan Tanah Kanisius. Yogyakarta.

Sari D. K, Hasanah. Y, Simanungkalit T, 2014 Respons Pertumbuhan Dan Produksi Beberapa Varietas Kedelai (Glycine Max L. (MERILL)) Dengan Pemberian Pupuk Organik Cair Fakultas Pertanian USU.

Simamora, S dan Salundik, 2006. Meningkatkan Kualitas Kompos. Cetakan Pertama. Agromedia Pustaka. Jakarta.
Smith, F. A. \& Smith, S. E. 2011. What is the significance of the arbuscular mycorrhizal colonisation of many economically important crop plants Plant Soil, 348, 63-79.

Supriyanto.1999. Respons Pertumbuhan Bibit Stek Mucuna (Mucuna Bracteata D.C) Pada Media Tanam Limbah Kelapa Sawit Dan Mikoriza Jurnal Agroekoteknologi USU vol 3(4);1586-1590.

Sembiring M, Jefri, Sakiah, Mardiana W, 2018. The inoculation of mycorrhiza and Talaromyces pinophilus toward the improvement in growth and phosphorus uptake of oil palm seedlings (Elaeis guineensis Jacq) on saline soil media. Bulgarian Journal of Agricultural science vol 24. 